\title{
Bathymetry and body size in marine gastropods: a shallow water perspective
}

\author{
Kaustuv Roy* \\ Section of Ecology, Behavior and Evolution, Division of Biology, University of California, San Diego, 9500 Gilman Drive, \\ La Jolla, California 92093-0116, USA
}

\begin{abstract}
Spatial patterns of species body size across major environmental gradients are being quantified for terrestrial organisms, but similar efforts are largely lacking for marine invertebrates. Bathymetry represents a major environmental gradient in the oceans, and existing theoretical models predict that species body size should decrease with increasing depth, especially for deep-sea species. Previous analyses of body size in deep-sea gastropods have shown size to increase with depth and hence contradict model predictions. In this study, I use data for 636 species of gastropods (in 10 major groups) living on the NE Pacific continental shelf to test hypotheses about processes that determine size-depth trends in marine gastropods. Results show that the gastropod family Turridae, a major component of both shallow-water and deep-sea biotas, shows similar size-depth trends in both environments but that predominantly shallow water families may show different patterns. In addition, size-depth trends may differ between clades and between different trophic groups. The implications of these results for better understanding the processes that underlie bathymetric trends in body size are discussed.
\end{abstract}

KEY WORDS: Body size $\cdot$ Bathymetry $\cdot$ Gastropoda

Resale or republication not permitted without written consent of the publisher

\section{INTRODUCTION}

Body size is considered to be one of the most important attributes of organisms (Peters 1983, Blackburn \& Gaston 1994, Brown 1995, West et al. 1997), and there is growing interest in understanding the processes that generate spatial patterns in body size, especially across major environmental gradients such as those associated with latitude, altitude and bathymetry (Cushman et al. 1993, Brown 1995, Blackburn \& Gaston 1996, Blackburn et al. 1999, Rex et al. 1999). However, these patterns remain poorly documented for invertebrates in general, and marine invertebrates in particular. Most studies of bathymetric trends in body size have focused on the deep sea, and existing theoretical models predict a decrease in species body size with increasing depth (Thiel 1975, Sebens 1987, Rex \& Etter 1998). The available empirical data on size-depth

*E-mail: kroy@biomail.ucsd.edu relationships in the deep sea suggest that such trends may differ among taxa (see Rex \& Etter 1998 for a review). However, whether some of these differences reflect sampling and different ways of quantifying body size, rather than true biological signals, remains a subject of debate (Rex \& Etter 1998, Rex et al. 1999).

In deep-sea gastropods, careful sampling and the use of standardized metrics have revealed a statistically significant trend for body size to increase with depth, within and among species (Rex \& Etter 1998, Rex et al. 1999). The processes underlying this surprising empirical pattern are uncertain but one hypothesis is that the trend results from selection favoring large sizes as food becomes more scarce with increasing depth (Rex et al. 1999). This is, however, difficult to test directly because of the inaccessibility of deep-sea habitats. In addition, other factors may also be important (Rex et al. 1999).

One approach to understanding the processes that control bathymetric trends in body size in marine 
invertebrates would be a comparison of deep-sea and shallow-water patterns within a single large group, because many of the factors that can influence bodysize distributions (e.g. nutrient input, temperature and biomass) vary significantly from the shelf to abyssal depths (Gage \& Tyler 1991). Thus, a comparative analysis of body size-depth relationships on the continental shelf versus the deep sea should be informative about the roles of these parameters in influencing body size. In addition, for invertebrate clades that range from the shallowest water to the deep sea, within-clade analyses of body size-depth trends should help separate the role of clade-specific adaptations from more general features of the environment.

Here, I take such a comparative approach and use body size and bathymetric data for 636 species of gastropods living on the NE Pacific continental shelf to test the food availability hypothesis and other potential mechanisms that might underlie the size-depth trends documented for deep-sea gastropods. In particular, I focus on 2 separate but related hypotheses. Hypothesis 1: The depth-related size trends in deep-sea gastropods result from some unique characteristics of the deep-sea environment. For example, the larger size of the deeper water species could result from the metabolic and competitive advantages of large size when food is extremely scarce (Peters 1983, Rex et al. 1999). Alternatively, since coastal and deep-sea environments are generally considered to be 'separate theaters of evolution' (Rex et al. 1999), the observed deepsea pattern could simply reflect the unique history of the deep sea. In either case, a particular gastropod clade that is a major constituent of both shallow-shelf and deep-sea faunas should show different size-depth trends in the 2 environments. This also suggests that the positive relationship between size and bathymetry observed by Rex et al. (1999) should characterize most deep-sea gastropods but should not be a common pattern among gastropod species on the continental shelf. Hypothesis 2: The size-depth trend in the deep-sea gastropods could reflect adaptations unique to the groups that have invaded the deep sea. This predicts that the shallower-water (i.e. continental-shelf) species of those gastropod groups that have successfully colonized the deep sea should also show a positive sizedepth relation. In general, this second hypothesis predicts that size-depth relationships should vary among clades rather than between environments.

\section{METHODS}

The data for this study were obtained from an existing database of eastern Pacific mollusks (Jablonski \& Valentine 1990, Roy et al. 1994, 1998, 2000a,b). The body size and bathymetric distribution (minimal and maximal depth of occurrence) of each gastropod species in this database were compiled through an exhaustive search of the primary literature and from major museum collections. The reported maximal depths of occurrence of shallow-water mollusk species can occasionally be inflated due to downshelf transport of dead shells (Kidwell \& Bosence 1991). Hence, for this study, wherever possible, I use the maximum reported depth of individuals collected alive as a measure of the bathymetric range limit for a species. Thus, my bathymetric data represent minimum estimates of the bathymetric ranges of species.

Previous studies have used a number of different measures to quantify body size, ranging from linear morphological dimensions (such as length) to estimates of body mass (Blackburn \& Gaston 1994, Rex et al. 1999). In this study, I use the geometric mean of length and height of the gastropod shell as a measure of size. This simple metric has been used by a number of previous workers and attempts to partially standardize for interspecific shape differences (Stanley 1986, Jablonski 1996, Jackson et al. 1996). This size metric is highly correlated with body mass as well as linear measurements of the gastropod shell (K. Roy \& D. Jablonski unpubl.). Thus, my results should be directly comparable to other studies that have used the length of the shell as a measure of size (e.g. Rex et al. 1999). Each species is represented in my analyses by its maximum reported size, rounded to the nearest $\mathrm{mm}$. For all the analyses, the body size data were log-transformed to normalize the size-frequency distributions.

Interspecific size-depth trends are best studied using closely related and ecologically similar species (Rex \& Etter 1998). The 10 major groups of gastropods used here represent a variety of feeding types (Table 1). For each group, I only included species that are restricted to the continental shelf $(<200 \mathrm{~m}$, see Sanders \& Hessler 1969). I quantified the body size-depth relationships for the individual families of gastropods in 3 different ways, each of which has its advantages and shortcomings: Method 1 uses regression of mean body size and water depth for all species occurring in $50 \mathrm{~m}$ depth increments; Method 2 regresses the body size of a species against the midpoint of its bathymetric range; and Method 3 regresses the body size of a species against its minimal depth of occurrence. Method 1 uses the range-through assumption that each species occurs everywhere throughout its bathymetric range. Since each species can occur in more than 1 depth bin, the data points in the regression are not independent, so the regression statistics should be interpreted conservatively. Methods 2 and 3 use each species only once in the regressions. However, Method 2 assumes that the observed minimum and maximum bathymetric 
Table 1. Families of NE Pacific gastropods used in this study and the species richness of each group

\begin{tabular}{|c|c|c|c|}
\hline Family & Trophic type & $\begin{array}{l}\text { Number of species } \\
\text { used in this study }\end{array}$ & $\begin{array}{l}\text { Total number of } \\
\text { NE Pacific species }\end{array}$ \\
\hline Turridae & Carnivorous & 232 & 317 \\
\hline Columbellidae & Carnivorous, herbivorous & 103 & 144 \\
\hline Epitoniidae & Parasitic & 59 & 64 \\
\hline Muricidae & Carnivorous & 80 & 102 \\
\hline Naticidae & Carnivorous & 25 & 39 \\
\hline Trochidae & Carnivorous, herbivorous & 72 & 79 \\
\hline Trochidae excluding Calliostominae & Herbivorous & 49 & 55 \\
\hline Calliostominae & Carnivorous & 23 & 24 \\
\hline Acmaeidae + Lotiidae & Herbivorous & 44 & 49 \\
\hline Conidae & Carnivorous & 21 & 26 \\
\hline
\end{tabular}

limits of each species are known without significant error (i.e. it does not allow for significant sampling errors); in contrast, Method 3 assumes that the observed minimum bathymetry of a species represents its true minimal depth limit. Thus, Method 1 is most robust to errors associated with sampling the actual depth limits of individual species, while Method 2 is most susceptible to such errors. In addition, Method 2 may also yield biased results if a large proportion of the species has very large bathymetric ranges since their midpoints would tend to fall in the mid-shelf region.

\section{RESULTS AND DISCUSSION}

In contrast to the deep sea, the size-depth relationship in shallow-water gastropods is variable and appears to be clade-specific, and the relationships may vary between carnivorous and non-carnivorous gastropods (Figs. 1 \& 2). Of the 10 gastropod groups analyzed here, body size increases significantly with depth in only 4 families, Turridae, Conidae, Columbellidae and Epitoniidae (Table 2). When the families are categorized by feeding types, significant increases in size with depth are found only among the carnivorous and parasitic families, while the herbivorous and grazing families show either a negative or non-significant relationship (Figs. 1 \& 2, Tables 1 \& 2). Such inverse relationships between size and depth are predicted by theoretical models (Thiel 1975, Sebens 1987) but appear to be absent in deep-sea gastropods (Rex et al. 1999). This could, however, reflect the lack of relevant data for many groups of deep-sea gastropods (e.g. Rex \& Etter 1998, Rex et al. 1999).

Two of the 3 families that show a significant increase in body size with depth in shallow water (Turridae and Epitoniidae) are also major components of the deep-
Table 2. Bathymetric trends in body size within gastropod families. See text for descriptions of the individual methods. Positive and negative denote trends that are significant at 0.05 level or less; ns: not significant

\begin{tabular}{|lccc|}
\hline Family & Method 1 & Method 2 & Method 3 \\
\hline Turridae & Positive & Positive & Positive \\
Columbellidae & Positive & Positive & Positive \\
Epitoniidae & Positive & ns & ns \\
Muricidae & Negative & ns & ns \\
Naticidae & $\mathrm{ns}$ & $\mathrm{ns}$ & $\mathrm{ns}$ \\
Trochidae & $\mathrm{ns}$ & $\mathrm{ns}$ & $\mathrm{ns}$ \\
Trochidae excluding & $\mathrm{ns}$ & Negative & Negative \\
Calliostominae & & & \\
Calliostominae & $\mathrm{ns}$ & $\mathrm{ns}$ & $\mathrm{ns}$ \\
Acmaeidae + Lotiidae & Negative & $\mathrm{ns}$ & $\mathrm{ns}$ \\
Conidae & Positive & $\mathrm{ns}$ & $\mathrm{ns}$ \\
\hline
\end{tabular}

sea gastropod fauna (Rex 1976, Bouchet \& Waren 1980, 1986). This consistency across such a broad bathymetric profile, along with the lack of a taxonomically pervasive size-depth trend in shallow-water clades, supports the hypothesis that the size-depth relationships in gastropods may be influenced more by cladespecific adaptations, or by membership in particular trophic groups, than by general environmental controls.

Small body size is a trait shared by most molluscan groups that have colonized the deep sea (Sanders et al. 1973, Grassle 1978, Allen 1979, Knudsen 1979, Lipps \& Hickman 1982, Allen \& Sanders 1996) and hence, the positive size-depth cline documented there only involves species at the small end of the molluscan size spectrum (Rex \& Etter 1998, Rex et al. 1999). In my data, positive size-depth relationships are also found in the 3 families that have the smallest mean body sizes of all the groups analyzed (Fig. 3). This suggests that positive size-depth relationships may be most common in 


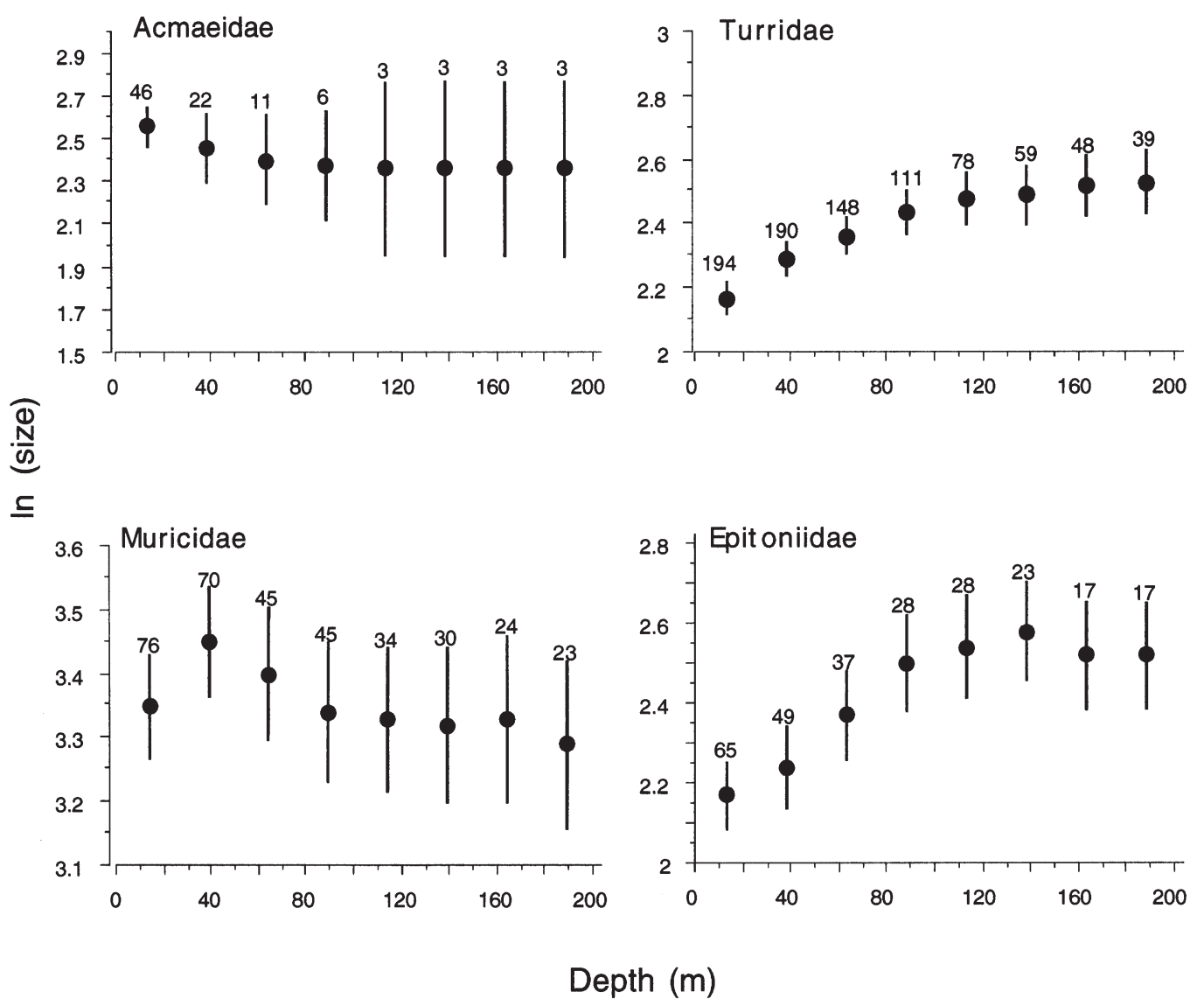

Fig. 1. Body size and depth in 4 families of marine gastropods on the NE Pacific continental shelf. Each point represents the mean of all species present in a $50 \mathrm{~m}$ depth bin plotted against the midpoint of the bin (see text). The error bars are \pm 1 SE of the mean. The numbers represent the species richness of the particular depth bin. See Table 2 for the relevant statistics

small gastropods and that the predominance of the pattern in the deep sea may, at least partially, be a consequence of the diminutive size of most species in that environment. Thus, these results indicate that the small sizes of the deep-sea gastropods and the positive size-depth clines may result from similar processes, rather than being driven by independent mechanisms, as previously suggested (Rex et al. 1999). The hypotheses that size-depth relationships are produced by clade-specific adaptations and that a positive trend is more common in groups with smaller-bodied species can be tested with size data from additional deep-sea gastropod clades as they become available. For example, the shallow-water patterns imply that deep-sea epitoniids should also show a positive size-depth relationship but that deep-sea trochids should not.

Very little is known about the processes that determine size-depth relationships in marine invertebrates. Thiel's $(1975,1979)$ size-structure hypothesis invoked the scarcity of food as the primary factor limiting body size in the deep sea. This model predicts a general decrease in size with increasing depth, a pattern not commonly found in deep sea gastropods (Rex et al.
1999). Similarly the optimality model of Sebens (1982, 1987), where the body size of a species reflects the balance between rates of energy intake (food acquisition) and the energetic costs, also suggests a decreasing trend in size with depth, although quantitative tests of this model are still lacking (Rex \& Etter 1998). In contrast, Rex et al. (1999) argued that lower food availability may actually select for increasing size due to the metabolic and competitive advantages of large size. While the availability of food may indeed play a role in driving bathymetric changes in body size, the fact that some gastropod families show the same size-depth trend both in shallow water and in the deep sea, raises the question as to how important food availability really is in determining size trends. For example, turrid gastropods are generalized predators that feed on polychaete worms, sipunculans and nemerteans (Beesley et al. 1998), and the density of polychaete prey decreases rapidly with depth (Thistle et al. 1985, Carrasco 1997, Cosson-Sarradin et al. 1998). Thus, food limitations for turrids should be much less severe on the continental shelf compared to the deep sea; however, turrid body size increases significantly with 
Turridae

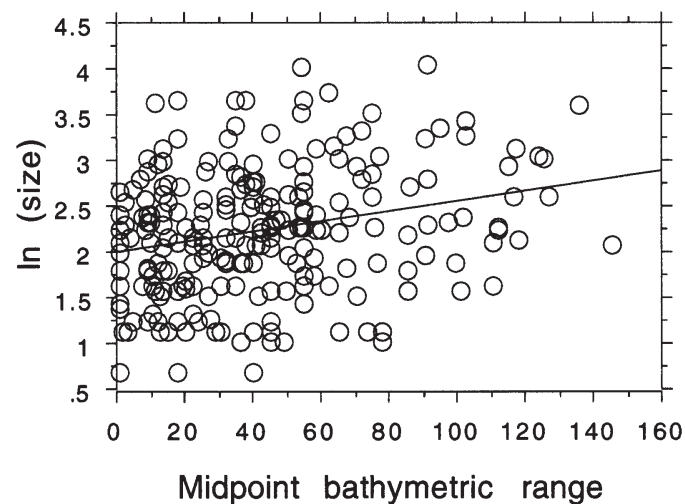

Naticidae

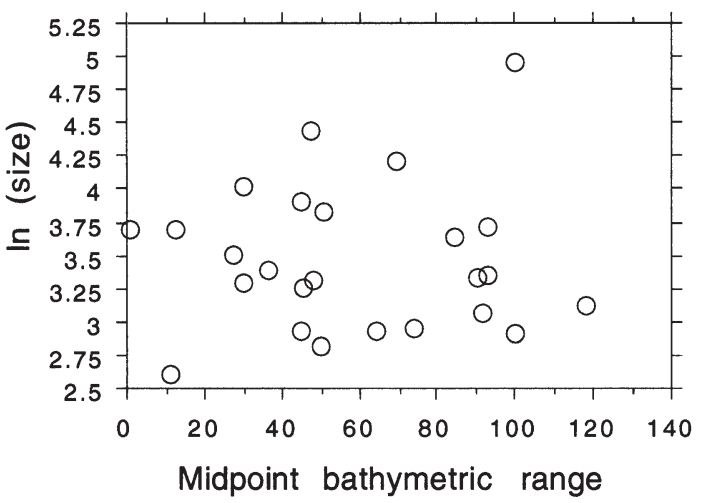

Columbellidae

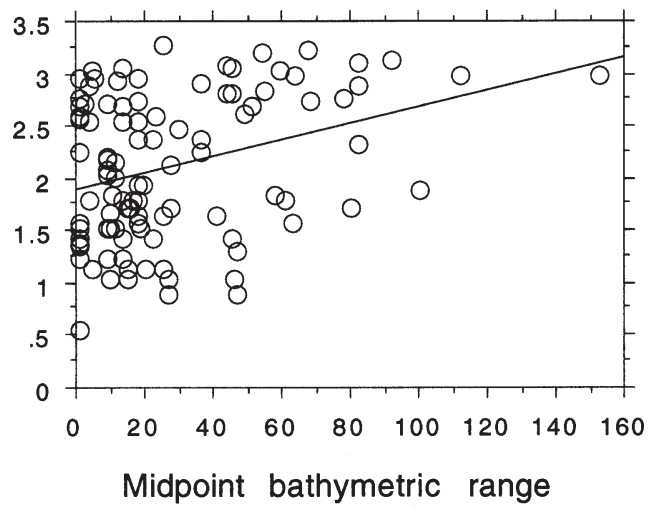

Trochidae (excluding Calliostominae)

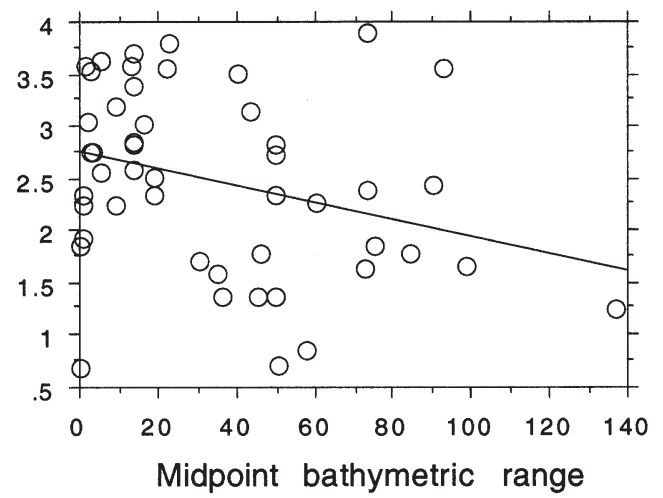

Fig. 2. Relationship between body size and midpoint of bathymetric range in 4 families of NE Pacific gastropods (see text for details of the method). Each point represents an individual species. Table 2 provides a summary of the statistics

depth in both habitats. In addition, prey capture methods in some turrids (e.g. Ophiodermella) are identical to those seen in species of Conus (Beesley et al. 1998), and the latter group, which is restricted to shallow waters, also appears to increase in size with depth on the NE Pacific continental shelf (Table 2). In general, overall biomass decreases exponentially with depth in the oceans (Rowe 1983) and hence, food limitation is unlikely to be the sole determinant of size-depth clines in shallow water. It is, of course, possible that the processes that determine within-clade size-depth relationships on the continental shelf are different from those operating in the deep sea. Such a hypothesis is difficult to test directly, but again, comparisons involving multiple deep-sea and shallow-water groups may provide some insight.

In addition to food availability, other aspects of the environment that vary with depth may also influence interspecific trends in body size. For example, recent studies have suggested that oxygen availability or the partial pressure of oxygen may influence ectotherm body size (Chapelle \& Peck 1999, Spicer \& Gaston 1999). Oxygen availability does change with depth in

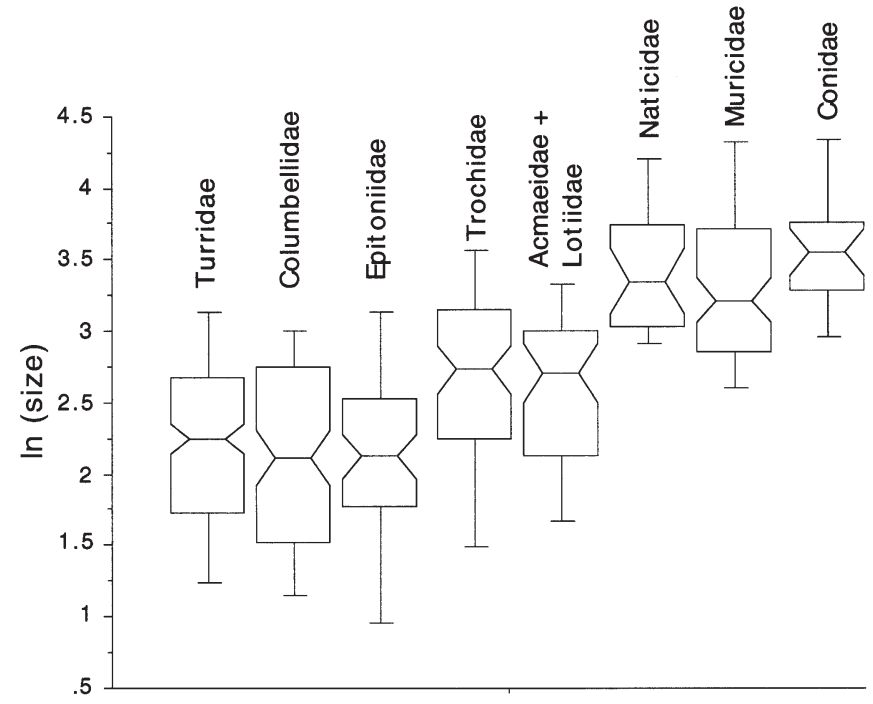

Fig. 3. Box plots showing the distribution of body size in each of the families of gastropods used in this study. The notch for each box shows the $95 \%$ confidence interval around the median. The horizon lines from the bottom to the top represent 10 th, 25th, 50th (median), 75th and 90th percentiles 
many oceanic regions (e.g. Sewell \& Fage 1948, World Ocean Database 1998) and could influence size-depth trends, although the effect is apparently not very strong in midwater fishes and crustaceans (see Spicer \& Gaston 1999).

A number of studies have focused on the latitudinal and altitudinal variations in body size in terrestrial organisms (Cushman et al. 1993, Barlow 1994, Brown 1995, Blackburn \& Gaston 1996, Hawkins \& DeVries 1996, Blackburn et al. 1999) but similar efforts are largely lacking in marine systems (but see Macpherson \& Duarte 1994, Roy et al. 2000a, Roy \& Martien 2001). The pattern of increasing size with depth in deep-sea gastropods, documented by Rex et al. (1999), is inconsistent with existing model predictions about sizedepth clines and raises interesting questions about the processes that drive such patterns. Results of this study show that the gastropod family Turridae, a major component of both shallow-water and deep-sea biotas, shows similar size-depth patterns in both environments but that predominantly shallow-water families may show different patterns. Whether the pattern seen in the turrids also holds for other groups that are well represented in both the deep sea and on the continental shelf, is currently unknown. Comparative analyses using data from multiple clades and from the shallow ocean as well as the deep sea are needed to better understand the processes that control the distributions of species body sizes in the ocean.

Acknowledgements. I thank D. Jablonski and J. W. Valentine for discussions, and A. J. Underwood and 2 anonymous reviewers for useful comments. This work was supported by NSF grant EAR-9903177.

\section{LITERATURE CITED}

Allen JA (1979) The adaptations and radiation of deep-sea bivalves. Sarsia 64:19-27

Allen JA, Sanders HL (1996) The zoogeography, diversity and origin of the deep-sea protobranch bivalves of the Atlantic: the epilogue. Prog Oceanogr 38:95-153

Barlow ND (1994) Size distributions of butterfly species and the effect of latitude on species size. Oikos 71:326-332

Beesley PL, Ross GJB, Wells A (eds) (1998) Mollusca: the southern synthesis. Fauna of Australia, Vol 5, Part B. CSIRO Publishing, Melbourne, p 565-1234

Blackburn TM, Gaston KJ (1994) Animal body size distributions: patterns, mechanisms and implications. TREE 9: 471-474

Blackburn TM, Gaston KJ (1996) Spatial patterns in the body sizes of bird species in the New World. Oikos 77:436-446

Blackburn TM, Gaston KJ, Loder N (1999) Geographic gradients in body size: a clarification of Bergmann's rule. Divers Distrib 5:165-174

Bouchet P, Waren A (1980) Revision of the north east Atlantic bathyal and abyssal Turridae (Mollusca, Gastropoda). J Molluscan Stud Suppl 8:1-119

Bouchet P, Waren A (1986) Revision of the northeast Atlantic bathyal and abyssal Aclididae, Eulimidae, Epitoniidae (Mollusca, Gastropoda). Boll Malacol Suppl 2:288-576

Brown JH (1995) Macroecology. University of Chicago Press, Chicago

Carrasco FD (1997) Sublittoral macrobenthic fauna off Punta Coloso, Antofagasta, northern Chile: high persistence of the polychaete assemblage. Bull Mar Sci 60:443-459

Chapelle G, Peck LS (1999) Polar gigantism dictated by oxygen availability. Nature 399:114-115

Cosson-Sarradin N, Sibuet M, Paterson GLJ, Vangriesheim A (1998) Polychaete diversity at tropical Atlantic deepsea sites: environmental effects. Mar Ecol Prog Ser 165: $173-185$

Cushman JH, Lawton JH, Manly BFJ (1993) Latitudinal patterns in European ant assemblages: variation in species richness and body size. Oecologia 95:30-37

Gage JD, Tyler PA (1991) Deep-sea biology. Cambridge University Press, New York

Grassle JF (1978) Diversity and population dynamics of benthic organisms. Oceanus 21:42-49

Hawkins BA, DeVries PJ (1996) Altitudinal gradients in the body sizes of Costa Rican butterflies. Acta Oecol 17: 185-194

Jablonski D (1996) Body size and macroevolution. In: Jablonski, D, Erwin DH, Lipps JH (eds) Evolutionary paleobiology. University of Chicago Press, Chicago, p 256-289

Jablonski D, Valentine JW (1990) From regional to total geographic ranges: testing the relationship in recent bivalves. Paleobiology 16:126-142

Jackson JBC, Jung P, Fortunato H (1996) Paciphilia revisited: Transisthmian evolution of the Strombina group. In: Jackson JBC, Budd AF, Coates AG (eds) Evolution and environment in tropical America. University of Chicago Press, Chicago, p 234-270

Kidwell SM, Bosence DWJ (1991) Taphonomy and timeaveraging of marine shelly faunas. In: Allison PA, Briggs DEG (eds) Taphonomy: releasing the data locked in the fossil record. Plenum Press, New York, p 115-209

Knudsen J (1979) Deep-sea bivalves. In: van der Spoel S, van Bruggen AC, Lever J (eds) Pathways in malacology. Bohn, Scheltema \& Holkema, Utrecht, p 195-224

Lipps JH, Hickman CS (1982) Origin, age, and evolution of Antarctic and deep-sea faunas. In: Ernst WG, Morin JG (eds) The environment of the deep sea. Prentice-Hall, New York, p 324-356

Macpherson E, Duarte CM (1994) Patterns in species richness, size and latitudinal range of East Atlantic fishes. Ecography 17:242-248

Peters RH (1983) The ecological implications of body size. Cambridge University Press, Cambridge

Rex MA (1976) Biological accommodation in the deep-sea benthos: comparative evidence on the importance of predation and productivity. Deep-Sea Res 23:975-987

Rex MA, Etter RJ (1998) Bathymetric patterns of body size: implications for deep-sea biodiversity. Deep-Sea Res II 45: 103-127

Rex MA, Etter RJ, Clain AJ, Hill MS (1999) Bathymetric patterns of body size in deep-sea gastropods. Evolution 53: 1298-1301

Rowe GT (1983) Biomass and production of the deep-sea macrobenthos. In: Rowe GT (ed) Deep-sea biology. WileyLiss, New York, p 97-121

Roy K, Martien KK (2001) Latitudinal distribution of body size in north-eastern Pacific marine bivalves. J Biogeogr 28: 485-493

Roy K, Jablonski D, Valentine JW (1994) Eastern Pacific molluscan provinces and latitudinal diversity gradient: no evi- 
dence for 'Rapoport's rule'. Proc Natl Acad Sci USA 91: 8871-8874

Roy K, Jablonski D, Valentine JW, Rosenberg G (1998) Marine latitudinal diversity gradients: tests of causal hypotheses. Proc Natl Acad Sci USA 95:3699-3702

Roy K, Jablonski D, Martien KK (2000a) Invariant sizefrequency distributions along a latitudinal gradient in marine bivalves. Proc Natl Acad Sci USA 97:13150-13155

Roy K, Jablonski D, Valentine JW (2000b) Dissecting latitudinal diversity gradients: functional groups and clades of marine bivalves. Proc R Soc Lond Ser B 267:293-299

Sanders HL, Allen JA (1973) Studies of deep-sea Protobranchia (Bivalvia); prologue and the Pristoglomidae. Bull Mus Comp Zool Harv Univ 145:237-262

Sanders HL, Hessler RR (1969) Ecology of the deep-sea benthos. Science 163:1419-1424

Sebens KP (1982) The limits to indeterminate growth: an optimal size model applied to passive suspension feeders. Ecology 63:209-222

Sebens KP (1987) The ecology of indeterminate growth in animals. Annu Rev Ecol Syst 18:371-407

Editorial responsibility: Otto Kinne (Editor),

Oldendorf/Luhe, Germany
Sewell RBS, Fage L (1948) Minimum oxygen layer in the ocean. Nature 162:949-951

Spicer JI, Gaston KJ (1999) Amphipod gigantism dictated by oxygen availability? Ecol Lett 2:397-403

Stanley SM (1986) Population size, extinction, and speciation: the fission effect in Neogene Bivalvia. Paleobiology 12: $89-110$

Thiel H (1975) The size structure of the deep-sea benthos. Int Rev Gesamten Hydrobiol 60:575-606

Thiel H (1979) Structural aspects of the deep-sea benthos. Ambio Spec Rep 6:25-31

Thistle D, Yingst JY, Fauchald K (1985) A deep-sea benthic community exposed to strong near-bottom currents on the Scotian Rise (western Atlantic). Mar Geol 66:91-112

West GB, Brown JH, Enquist BJ (1997) A general model for the origin of allometric scaling laws in biology. Science 276:122-126

World Ocean Database (1998) US Department of Commerce, National Oceanic and Atmospheric Administration, National Environmental Satellite, Data, and Information Service, Silver Springs, MD

Submitted: July 24, 2000; Accepted: February 28, 2002

Proofs received from author(s): June 25, 2002 